\title{
Climate, conflict, and social stability: what does the evidence say?
}

\author{
Solomon M. Hsiang • Marshall Burke
}

Received: 6 August 2012 / Accepted: 30 July 2013 / Published online: 17 October 2013

(C) Springer Science+Business Media Dordrecht 2014

\begin{abstract}
Are violent conflict and socio-political stability associated with changes in climatological variables? We examine 50 rigorous quantitative studies on this question and find consistent support for a causal association between climatological changes and various conflict outcomes, at spatial scales ranging from individual buildings to the entire globe and at temporal scales ranging from an anomalous hour to an anomalous millennium. Multiple mechanisms that could explain this association have been proposed and are sometimes supported by findings, but the literature is currently unable to decisively exclude any proposed pathway. Several mechanisms likely contribute to the outcomes that we observe.
\end{abstract}

This article is part of a Special Issue on "Climate and Security: Evidence, Emerging Risks, and a New Agenda” edited by François Gemenne, Neil Adger, Jon Barnett, and Geoff Dabelko.

Electronic supplementary material The online version of this article (doi:10.1007/s10584-013-0868-3) contains supplementary material, which is available to authorized users.

\section{S. M. Hsiang}

Woodrow Wilson School of Public and International Affairs, Princeton University, Princeton, NJ 08544, USA

S. M. Hsiang

National Bureau of Economic Research, Cambridge, MA 02138, USA

M. Burke

Department of Agricultural and Resource Economics, University of California, Berkeley, Berkeley, CA 94720, USA

e-mail: marshall.burke@berkeley.edu

Present Address:

S. M. Hsiang $(\varangle)$

Goldman School of Public Policy, University of California, Berkeley,

Berkeley, CA 94720, USA

e-mail: shsiang@berkeley.edu 


\section{Introduction}

Many factors influence the peacefulness and stability of societies. In this review, we ask whether the existing scientific evidence implicates climatological changes as one of these factors. While the relationship between climate and social stability has long been a topic of both academic and popular interest, recent improvements in computing power, data quality, and methods for causal inference have culminated in a sudden explosion of rigorous quantitative analyses that have greatly expanded our knowledge on the topic. The majority of these studies are very recent, with both the median (2010) and modal (2012) publication dates subsequent to the release of the latest Fourth Assessment Report (2007) of the Intergovernmental Panel on Climate Change (IPCC).

Literatures in archeological/paleo-climatological studies, psychology studies, political science studies and econometric studies provide insight into the possible association between climate and conflict or instability. We organize these works into two categories based on the period of observation, which is loosely associated with the duration of climatic events that are examined. Both categories exhibit a relative advantage. First, statistical studies of modern data focus on patterns of violence or political instability that respond to rapid changes (hourly to annual) in climatic variables, allowing the researcher to be confident that potential confounding variables in the exposed population are relatively constant. These studies are "well identified" in the sense that they most closely approximate a scientific experiment, where treatment (eg. climate $A$ ) and control (climate $B$ ) status is randomly assigned to populations (Holland 1986; Freedman 1991; Angrist and Pischke 2008).

In contrast, studies of historical time series can discern patterns of social instability over substantially longer time-scales, probing deep history and thereby examining social responses to more gradual variations (decadal to millennial) in regional climates. Though these studies are less well identified-human societies may change substantially over these longer timescales - they are able to examine "low frequency" changes in climate that perhaps more closely resemble expected future anthropogenic climate changes. We term this general inability of any study to be well identified while simultaneously examining low frequency climatic changes the "frequency-identification tradeoff," noting that it results from a general mismatch between the rate at which the climate will change (gradual) and the rate at which human societies evolve (rapid). Resolving this mismatch has proven difficult for empiricists with no established "best approach." In order to rigorously assess the literature we examine the full spectrum of studies along the entire frequencyidentification frontier.

In this review we examine the impact of climatological changes on conflict, violence and instability in various social and political systems. We focus attention on those quantitative data-based studies that meet a rigorous empirical standard for making credible causal claims. At the time of writing, we obtained 50 independent studies that met this minimum criteria for inclusion, representing the cumulative research effort of over 160 authors examining 37 distinct data sets published in 21 distinct journals. We list these studies in Appendix Tables A.1-A.2. In a companion paper, we reanalyze the raw data from many of these papers and conduct a quantitative meta-analysis of their results (Hsiang et al. 2013). 
In recent articles, Bernauer et al. (2012), Gleditsch (2012) and Scheffran et al. (2012) describe some recent progress in this literature and arrive at largely different conclusions than those presented here. We maintain this discrepancy is primarily due to (1) our use of different and more stringent methodological standards, and (2) we examine more data. Of the 37 conflict data sets considered here, these prior studies examine four (11\%), five (14\%) and three ( $8 \%$ ) data sets, respectively. Combined, these articles consider 12 of the 50 primary studies reviewed here. Other differences between those studies and this review are detailed in the Online Appendix.

\subsection{Defining important terms}

In this article, we use the terms climate, conflict and social stability to describe broad classes of independent and dependent variables. We use causality according to its formal statistical interpretation.

Climate We use climate to refer to observations of climatic variables: temperature, rainfall, and water availability - these variables may be averaged over long or short observational periods. Some authors argue that short averaging periods (e.g. annual) only describe the "weather" or "climate variability" and thus have little to say about the impact of "climate." We think this view is incorrect. Societies experience climatic variables in continuous time and respond to both short-lived and long-term changes, making the frequency of short-lived events a socially-relevant feature of the climate. For example, if hot temperatures increase the likelihood of riots in a cityeven if only experienced for a few hours - then this is important for understanding climate impacts because the frequency of these momentary events may change if the distribution of daily temperatures changes.

Conflict and Social Instability We use the terms conflict and social instability ("conflict" for brevity) to describe events where regular patterns of dispute resolution fail or social orders change. These events may or may not be violent in nature, they may involve individuals or groups of individuals, they may be organized or disorganized, and they may be personally, politically or otherwise motivated. Most studies examine only one type of conflict at a time, however we examine this comprehensive set of outcomes because it appears that many of these patterns are potentially related and that their responses to climate exhibit certain commonalities. For this reason it is likely that evaluating these phenomena together might help us better understand each individually.

Causality We use the standard definition of causality proposed by Rubin (1974) for quantitative research. A change in climate is determined to be a cause of human conflict if an exogenous change in climate is associated with a measurable change in a population's risk of conflict relative to an otherwise plausibly identical comparison population (see Holland (1986), Freedman (1991), Angrist and Pischke (2008) and the Online Appendix for discussions). Importantly, this definition allows us to infer causality through quantitative measurements even if the detailed pathway linking a cause to its effect is not fully understood. Some authors have argued that a causal effect of climate on conflict cannot be inferred without identifying a complete 
causal chain of mechanisms (Sutton et al. 2010; Buhaug 2010), however this is not true (Rubin 1974; Holland 1986; Freedman 1991; Angrist and Pischke 2008). If inference without precise causal pathways were not possible, individuals who do not understand the thermodynamics of a car engine could not infer whether or not stepping on a car's accelerator pedal caused the car to move forward. We note that this definition of causality does not imply that climate is the only cause of human conflict or that mediating factors are unimportant. Conflict has many causal and mediating factors, and we may identify climate as one of those factors if it exerts a measurable effect on conflict holding these other factors fixed.

\subsection{Summary of findings}

Once attention is restricted to those studies capable of making causal claims, a growing consensus emerges from the recent literature: we find strong support for a causal association between climatological changes and conflict across a range of geographies, a range of different time periods, a range of spatial scales and across climatic events of different duration. Although some disagreement between studies remains, many purported discrepancies disappear when a common statistical approach is employed and hypothesis tests are carefully interpreted (see companion analysis in Hsiang et al. (2013)). The state of knowledge in this field is similar to that of epidemiologists studying the link between smoking tobacco and lung cancer in the 1930's (Witschi 2001): there is clear evidence of a causal association from statistical analyses but the underlying mechanism, which is more difficult to disentangle, cannot yet be separated from alternative explanations.

Strength of the evidence for a causal association between climate variables and conflict or instability Appendix Tables A.1-A.2 list the 50 studies meeting our criteria for review. Ten are archeological/paleo-climatological studies that report associations between climatic changes and social stability but do not conduct formal hypothesis tests of this association. Of the remaining 40 studies, 31 (78\%) report associations that are large and statistically significant, ${ }^{1}$ eight $(20 \%)$ report uncertain results that fail to reject large associations and zero association, ${ }^{2}$ and one study $(2.5 \%)$ rejects the hypothesis of a large association.

Consistency across regions and time periods Associations between climate and conflict are documented in studies that span Africa, the Americas, and Eurasia, with the oldest sample beginning before $8000 \mathrm{BCE}$ and the latest sample ending in 2010 . Eight modern studies documenting a significant association are fully global in their coverage.

Consistency across the duration of climatic events It is sometimes hypothesized that gradual climatic changes will have little or no impact on conflict because they

\footnotetext{
${ }^{1}$ We define a "large effect size" to be an effect that the authors deem "large" or is greater than $10 \%$ of the mean risk level per standard deviation in the independent climate variable. "Statistically significant" here means that there is less than a $5 \%$ chance of observing the effect size that was observed if there was in fact no effect (i.e. $p<0.05$ ).

${ }^{2}$ Three reject zero association at the $10 \%$ level but not at the $5 \%$ level.
} 
are easier to manage than abrupt climatic "shocks" (Gleditsch 2012). However, the evidence does not support this hypothesis. Instead, previous studies document associations between climate and conflict at all temporal scales, ranging from a climatologically anomalous hour to an anomalous millennium.

Consistency across spatial scales Roughly half of studies that measure an association between climate and conflict use data aggregated to the country level, but the literature also documents associations at all scales ranging from site-level data (e.g. a laboratory or sports arena) to globally-aggregated data. There is no evidence that climatic events simply displace conflicts in space.

The direction of the effect While an increasing risk of conflict has been associated with extreme rainfall or temperatures in either direction, the most robust association across studies is the increase in conflict associated with increasing surface temperature in locations that are temperate or warm on average. In general, the climatic events that increase the risk of conflict are similar to the events that would have an adverse effect on agriculture (Schlenker and Roberts 2009; Lobell and Burke 2010) or human productivity (Hsiang 2010; Graff Zivin and Neidell 2013).

The size of the effect In archeological/paleo-climatological studies, the magnitude of the climate's influence is difficult to articulate because the universe of societies is not well-specified. However in studies where the risk of conflict is well-defined, climatological factors are generally associated with large movements in risk. For example, in many studies, historical doublings of risk can be attributed to observed changes in climatological variables.

\subsection{Criteria for inclusion in this review}

We review quantitative studies that use the strongest experimental or quasiexperimental research designs, restricting our focus to those studies that meet modern standards for measuring causal effects (Holland 1986; Freedman 1991; Angrist and Pischke 2008). Put simply, meeting this standard requires that the independent variables describing climate are very likely uncorrelated with other unobserved variables that might affect the conflict variable.

In particular, to ensure that changes in sample composition do not drive a study's findings (see Appendix Figure 1), we only consider studies that follow individual populations inhabiting fixed locations over time-giving us the greatest possible confidence that the populations examined are endowed with traits that are constant or very similar between sequential observations. Because linear trends for any two variables will always be correlated (see Appendix Figure 2), we also only evaluate studies where data are detrended and populations are followed through both positive and negative (i.e. non-monotonic) changes in the independent variable[s] of interest. To operationalize this criteria we only include studies that exhibit timeseries variation in independent variables, that contain location-specific fixed effects (in panel data) and that account for trends either parametrically (eg. locationspecific trends) or non-parametrically (eg. common period fixed effects). Crosssectional studies, which we do not include, do not keep populations fixed but instead compare multiple contemporaneous populations with one another, attributing their different properties to the different climates that they inhabit. This approach may 
be reliable under certain restrictive conditions (Angrist and Pischke 2008), but these conditions are unlikely to be satisfied in studies of climate and conflict. For example, a comparison of contemporaneous countries across Africa, as done in Buhaug (2010), ${ }^{3}$ must assume that all countries are identical to one another in all respects except the traits that are explicitly accounted for in a model-an assumption that is rarely justified in these contexts (typically, these comparisons require the implausible assumption that culture, colonial history, geography, infrastructure, healthcare and numerous other factors do not affect conflict). Finally, we consider studies to be unique if they examine a distinct pairing of dependent and independent variables over a novel sample. If a follow-up analysis uses identical data, we count the entire sequence of papers as a single "study", adjusting the conclusions we draw from that study to reflect the larger discussion.

Our overall approach is purposefully conservative, in the sense that we only draw inferences from studies that meet a high methodological standard. We provide a detailed explanation of the statistical issues that motivate our selection criteria in the Online Appendix. We do not argue that studies that do not meet our standard contribute no information to the debate. Rather, we simply focus on the set of studies that meet the highest standard of rigor.

For expositional purposes, we divide the empirical literature based on whether the data they analyze begin before or after 1900 CE. This cutoff is convenient for many reasons: (1) studies of pre-1900 samples examine long time-series while studies of post-1900 samples generally examine shorter panel data; (2) many pre-1900 samples examine lower-frequency climate changes that are absent from post-1900 datasets; and (3) pre-1900 samples come from archeology/paleo-climatology or economics, while post-1900 samples are from psychology, political science or economics.

\section{Findings from pre-1900 samples}

Because studies of samples from before 1900 can examine multi-century datasets, several $^{4}$ are uniquely positioned to examine prolonged perturbations in a location's climate. These natural climate variations represent an appealing proxy for future anthropogenic changes because they are gradual and persistent. However, societies exposed to these changes may have been somewhat different from earlier or later societies. Since it is difficult to know if these gradual social changes confound estimates of gradual climatic influences, studies of slow change may be imperfectly identified, representing one extreme of the "frequency-identification tradeoff," and should thus be interpreted with some caution.

When considering pre-1900 data, it is important to ask whether these historical societies are a reasonable analog to modern populations. Societies have changed in

\footnotetext{
${ }^{3}$ Buhaug (2010) accounts only for average income, an index of political exclusion, and conflict in the previous year.

${ }^{4}$ Not all studies of pre-1900 samples examine low-frequency changes, for example Stahle et al. (1998) and Chaney (2013) both examine climatic events lasting 1-5 years.
} 
recent centuries (e.g. technological innovations), yet there remain locations where the state of economic development is near that of the societies in these pre-1900 samples (Maddison 2010). For examples, Appendix Table 1 list some countries that have modern average incomes close to that of Mexico near the time of the Mayan collapse $(\sim \$ 400)$, China at the time the Ming Dynasty fell $(\sim \$ 600)$ and the United Kingdom during the Little Ice Age $(\sim 1000)$, events that are discussed below. Income is a coarse and imperfect measure of economic and political development, nonetheless it is a powerful predictor of both average conflict levels (Blattman and Miguel 2010) and a society's sensitivity to climatic changes (Hsiang et al. 2011), suggesting that studies of pre-1900 samples-while perhaps not applicable to all current populations-are likely relevant for many poor societies in the modern world. However, importantly, such comparisons to the modern world should be made with reasonable caution as many non-income conditions, such as the global technological frontier, have changed since the periods examined in these studies.

\subsection{Africa and the Middle East}

Examining the "green Sahara" during 8000-1500 BCE, Kuper and Kröpelin (2006) document the widespread abandonment of settlements at the onset of rapid drying around 5300 BCE. Further east, Cullen et al. (2000) use marine sediment cores from the Gulf of Oman to demonstrate that the abrupt collapse of the Akkadian Empire in Mesopotamia around $2100 \mathrm{BCE}$ was associated with a rapid and unprecedented drying of that region.

Looking two millennia later, Chaney (2013) uses official records of Nile flood levels during 641-1438 to show that extreme anomalous floods devastated Egyptian

Table 1 Some countries with a modern income near that of Mexico at the time when the Mayan Empire collapsed (circa 900) (Haug et al. 2003), near that of China at the time when the Ming Dynasty fell (circa 1600) (Yancheva et al. 2007), and that of the United Kingdom during the Little Ice Age (circa 1600) (Tol and Wagner 2010)

\begin{tabular}{|c|c|c|c|c|c|}
\hline \multicolumn{2}{|c|}{$\begin{array}{l}\text { Mexico, c. } 900 \\
(\text { Mayan collapse) } \\
\text { income per capita } \sim \$ 400\end{array}$} & \multicolumn{2}{|c|}{$\begin{array}{l}\text { China, c. } 1600 \\
\text { (Fall of Ming Dynasty) } \\
\text { income per capita } \sim \$ 600 \\
\end{array}$} & \multicolumn{2}{|c|}{$\begin{array}{l}\text { United Kingdom, c. } 1600 \\
\text { (Little Ice Age) } \\
\text { income per capita } \sim \$ 1000\end{array}$} \\
\hline $\begin{array}{l}\text { Country } \\
\text { (in 2008) }\end{array}$ & $\begin{array}{l}\text { Per Cap GDP } \\
\text { (1990 dollars) }\end{array}$ & $\begin{array}{l}\text { Country } \\
\text { (in 2008) }\end{array}$ & $\begin{array}{l}\text { Per Cap GDP } \\
\text { (1990 dollars) }\end{array}$ & $\begin{array}{l}\text { Country } \\
\text { (in 2008) }\end{array}$ & $\begin{array}{l}\text { Per Cap GDP } \\
\text { (1990 dollars) }\end{array}$ \\
\hline Burundi & 479 & Afghanistan & 869 & Côte d'Ivoire & 1,095 \\
\hline Cent. Afr. Rep. & 536 & Chad & 706 & Djibouti & 1,254 \\
\hline Comoro Islands & 549 & Haiti & 686 & Iraq & 1,049 \\
\hline Dem. Rep. Congo & 249 & Guinea & 628 & Kenya & 1,098 \\
\hline \multirow[t]{7}{*}{ Niger } & 514 & Liberia & 802 & Mali & 1,145 \\
\hline & & Madagascar & 730 & Mauritania & 1,299 \\
\hline & & Malawi & 744 & Mongolia & 1,001 \\
\hline & & Sierra Leone & 686 & Rwanda & 1,020 \\
\hline & & Tanzania & 744 & The Gambia & 1,043 \\
\hline & & Zambia & 845 & Somalia & 978 \\
\hline & & Zimbabwe & 779 & Uganda & 1,008 \\
\hline
\end{tabular}

Source: Maddison (2010) 
agriculture and destabilized the political balance in medieval Egypt, causing the irregular dismissal of politically appointed religious authorities.

\subsection{The Americas}

Haug et al. (2003) reconstruct a two-thousand year record of climate in the Yucatan of Mexico by examining ocean sediment cores from the Cariaco Basin. They show that extreme droughts coincided with both the "Pre-Classical Abandonment" of early Mayan cities as well as the three periods of terminal abandonment six centuries later. The collapse of Mayan civilization occurred during sequential multi-year megadroughts superimposed on two centuries of prolonged dryness, a climate that differed qualitatively from the wetter six-hundred year climate in which the civilization developed. More recent work by Kennett et al. (2012) confirmed this relationship using a rainfall reconstruction from stalagmites in Belize.

During an overlapping period in Peru (500-1600), the Moche empire "adapted" to semi-millenial oscillations in precipitation, observable via ice-cores in nearby glaciers, by "breaking down" and reestablishing their civilization in either the coastal or highland regions (DeMenocal 2001 and citations). The Tiwanaku civilization, which built cities on the Bolivian-Peruvian altiplano surrounding Lake Titicaca, abruptly abandoned crop cultivation near 1100 and gradually abandoned urban centers during the same drying events that affected the Moche (DeMenocal 2001 and citations).

The following century, the first English colony in North America, on Roanoke Island, mysteriously disappeared in 1587 . By reconstructing a Palmer hydrological drought index (PHDI) with tree-ring cores, Stahle et al. (1998) demonstrate that this "Lost Colony" vanished during the region's most extreme three-year drought in eight-centuries. Jamestown Colony, settled nearby two decades later, almost collapsed during a similar drought.

\subsection{Asia}

Zhang et al. (2006) examine Chinese records from 1000-1911 and find cold periods of 10-100 years were associated with higher frequencies of war, rebellion, population decline and all five dynastic transitions. Zhang et al. argue that in temperate China, cold temperatures reduced yields, triggering civil unrest and political instability.

Taking a different approach, Yancheva et al. (2007) estimate the historical strength of China's summer monsoon during sixteen millennia using sediment cores from Lake Huguang Maar. Examining dynastic transitions between $2183 \mathrm{BCE}$ and $1644 \mathrm{CE}$, Yancheva et al. find that nearly every dynasty was established during a relatively wet period and declined or collapsed during a colder period of persistent dryness, many of which onset abruptly. The monsoon weakening that accompanied the Tang Dynasty's decline was driven by the same global climatic changes that dried the Yucatan during the Mayan collapse (Yancheva et al. 2007; Haug et al. 2003).

Bai and Kung (2010) use imperial records spanning 220-1839 to show that drier decades exhibited more conflict between the Chinese state and the nomadic population to its north. During periods of low rainfall, nomadic attacks on the 
sedentary Chinese population were more frequent. Similarly, using county-level data from China over the period 1651-1910, Kung and Ma (2012) find that periods of extreme drought or flood triggered "peasant rebellions" in rural areas, which primarily consisted of banditry against wealthy citizens.

In modern day Cambodia, Buckley et al. (2010) demonstrate that the collapse of the Angkor city-state in 1431 immediately followed two mega-droughts twenty years apart, each spanning multiple decades. Buckley et al. also provide qualitative evidence that the hydraulic engineers of Angkor, whose water management system covered $1000 \mathrm{~km}^{2}$, tried to adapt to these events with infrastructure adjustments. Despite their ingenuity, Angkor did not survive the contraction of its agricultural base and a conflict with the neighboring Siamese kingdom which escalated during the 50 years of dry conditions.

\subsection{Europe}

Consistent with findings from China, studies find that regional cooling and drying lead to increasing rates of organized inter-group violence in Europe. Examining 1400-1900, Zhang et al. (2007) document two periods (150 and $50 \mathrm{yrs)}$ of heightened violence that correspond with cold periods of the Little Ice Age. Zhang et al. (2011) revisit this period and argue (via Granger causality) that these cold episodes reduced crop yields, causing economic contractions that lead to war. Zhang et al. also find coincident health impacts and migrations throughout Europe, but no evidence that these pathways directly contributed to the outbreak of conflict.

Studying Europe for a longer period (1000-1990), Tol and Wagner (2010) find a positive association between wars and anomalously cold periods roughly 5-10 years long. However, this association disappears abruptly between 1700-1750, the period when Europe transitioned between a multi-century cold/violent period and a warmer/peaceful period (Zhang et al. 2011). This suggests that temporary cooling superimposed on cold baseline conditions have a larger effect on conflict than cooling during warm periods.

Using tree rings, Büntgen et al. (2011) also show that anomalously low temperatures were associated with periods of turmoil in Europe, including the "Migration Period" (c. 400-500), the 30 Years War (c. 1600), and migration to the Americas (c. 1800). Examining near-shore mollusk shells, Patterson et al. (2010) show that Nordic settlements in Iceland began during warm periods (c. 800-1000), but suffered famine and were abandoned after temperatures rapidly cooled $6^{\circ} \mathrm{C}(1000-1100)$. Greenland settlements were similarly abandoned during a cold period c. 1400 .

These findings from temperate Europe match the response of crop yields to temperature variation. Most staple grains exhibit an optimum growing temperature, and large departures from this optimum cause substantial declines in yields (Schlenker and Roberts 2009; Lobell and Burke 2010). When temperatures are cold on average, further cooling would have likely reduced yields. This suggests, but does not prove, that agriculture may have mediated the link between cooling and conflict.

Finally, in the most recent pre-1900 data, Mehlum et al. (2006) find that violent crime in Bavaria (1835-1861) rose in years following low rainfall. Mehlum et al. 
also show that rye prices rose and real wages fell the year after low rainfall, again suggesting that agro-economic factors might be mediating a link between rainfall and violence.

\section{Findings from post-1900 samples}

The resolution and generally high quality of post-1900 data allow researchers to match high frequency climatic changes with precisely timed human responses, something that is often not possible with earlier data. Moreover, because the data in these studies is modern (post-1950), estimated effects appear representative of the global population's current sensitivity to climatic changes. For these reasons, when compared to studies of pre-1900 data, studies of modern data estimate associations that are generally "better identified," in the sense of allowing us to infer causality (see Online Appendix), and they are arguably more relevant to the modern world. However because modern data sets are at most a few decades in length, they have difficulty characterizing the responses of populations to climatic changes with moderate-frequencies (eg. decadal variations) and have no ability to describe responses to lower-frequency changes (eg. on the scale of centuries or millennia). Thus, studies of post-1900 data are opposite most studies of pre-1900 data in terms of the "frequency-identification tradeoff."

\subsection{Africa-only data}

Africa is the most heavily studied region using modern data. In a seminal paper, Miguel et al. (2004) examine whether changes in rainfall lead to a higher or lower likelihood of civil conflict in Sub-Saharan countries (1979-1999). They find that when rainfall growth was negative, economic output contracted the following year and the likelihood of conflict increased. A subsequent debate has sprung up over the most appropriate statistics that should be used to summarize climate variables (Ciccone 2011; Miguel and Satyanath 2011) — a debate relevant to all studies in this review, as many variables have been employed in different contexts ${ }^{5}$ and no study has yet systematically evaluated which measure is "best" or even if different measures capture fundamentally different characteristics of climate.

The approach of Miguel et al. was revisited in Burke et al. (2009) who adjust the statistical model to simultaneously control for rainfall changes and temperature changes over 1981-2002, a potentially important adjustment since temperature and rainfall variations are correlated over time. Burke et al. continue to find that total rainfall is negatively associated with civil war incidence but discover that temperature is positively correlated with the civil war incidence, with the latter association appearing to be relatively stronger and more robust. While this finding was criticized for not establishing the precise causal pathway through which temperature lead to conflict (Sutton et al. 2010), this inability does not prohibit Burke et al. from drawing causal inferences (Burke et al. 2010c).

\footnotetext{
${ }^{5}$ For example, studies that follow have utilized the Palmer Drought Severity Index, the Weighted Anomaly Standardized Precipitation Index, the Standardized Precipitation-Evapotraspiration Index and absolute rainfall deviation to describe seasonal rainfall.
} 
A critique of Burke et al. by Buhaug (2010) demonstrated that changing the battle-deaths threshold used to define civil war caused the correlation described in Burke et al. to no longer be statistically distinguishable from zero. While this result weakens the finding of Burke et al. in a specific way, it was widely overinterpreted as disproof of the Burke et al. finding (Bernauer et al. 2012; Scheffran et al. 2012). The uncertainty in Buhaug's estimates are large, causing them to not be statistically distinguishable from the original estimate of Burke et al. and preventing the study from ruling out large effects of climate on conflict. For more on this issue, see the discussion of confidence intervals in the Online Appendix. Buhaug also argued that unobserved differences across populations should not be controlled for, but, as discussed earlier and in the Online Appendix, this approach is unlikely to provide valid results. ${ }^{6}$ A simple statistical test for the joint significance of these elements of the Burke et al model rejects Buhaug's hypothesis that these terms are unimportant. ${ }^{7}$

Other country-level studies report results that are broadly consistent with the original findings of Miguel et al. (2004) and Burke et al. (2009). Brückner and Ciccone (2011) examine the destabilization of non-democratic regimes and find that these typically violent transitions are more likely during hot and dry periods (1980-2004). Couttenier and Soubeyran (2013) employ the basic model used in Burke et al. (2009) but use the Palmer Drought Severity Index as the independent variable, finding that civil conflict for the period 1957-2005 is more likely when water availability is low, and that this result remains statistically different from zero under the battery of tests proposed by Buhaug (2010). Cervellati et al. (2011) show that the impact of low rainfall on civil conflict is larger for countries with higher infectious disease incidence, perhaps suggesting that the disease environment might mediate the effect of climate on conflict. Hendrix and Salehyan (2012) model small scale conflicts such as riots, protests, government repression and coups (19912007), finding that extremely low or high rainfall anomalies are associated with these conflicts.

Recent efforts have examined associations between violence in Africa and climatic changes using gridded data that ignore national boundaries. Harari and La Ferrara (2011) construct a $1^{\circ}$ grid of conflicts covering all of Africa during 1960-2010, Pasquale and Travaglianti (2009) construct a $2.5^{\circ}$ grid over Sub-Saharan Africa during 1979-2008, O'Loughlin et al. (2012) construct a $1^{\circ}$ grid of conflicts in nine East African countries, and Theisen (2012) constructs a $0.25^{\circ}$ grid of small and large scale conflicts in Kenya during 1989-2004. All of these high-resolution gridded studies find that combinations of temperature and precipitation changes are associated with violent conflict, ${ }^{8}$ with effect sizes that tend to be larger (in percentage terms) but are otherwise broadly in agreement with the earlier country-level analyses. In a similar approach, Fjelde and von Uexkull (2012) match rainfall data and nonstate conflict data using subnational administrative boundaries, finding that negative

\footnotetext{
${ }^{6}$ See also Burke et al. (2010a) and Burke et al. (2010b).

${ }^{7}$ An F-test rejects the hypothesis country fixed effects are the same across countries $(\mathrm{p}<0.001)$.

${ }^{8}$ Theisen (2012) estimates a model of conflict risk that is quadratic in temperature but does not test whether the marginal effect of temperature is zero or not. In a Supplementary Appendix, Theisen showed that in a linear model that properly tested the marginal effect of temperature, it had a positive and significant effect on both conflict $(\mathrm{p}<0.1)$ and conflict events $(\mathrm{p}<0.05)$ (personal correspondence with author dated November 19, 2012).
} 
rainfall anomalies increase the risk of non-state conflict. Theisen et al. (2011) use subnational gridded data but obtain ambiguous results that do not reject zero effect and do not reject large effects.

Finally, in the African study with the highest spatial resolution, Miguel (2005) examines personal violence in Tanzanian villages (1992-2002) and demonstrates that murders of women accused of being witches rise in when local rainfall is extremely low or high.

\subsection{The Americas, Europe and Asia}

Large scale inter-group violence has also been associated with climatic fluctuations outside of Africa. Bohlken and Sergenti (2010) and Sarsons (2011) find that negative rainfall growth is associated with higher risk of Hindu-Muslim riots in Indian states over the last few decades of the 20th century. Sarsons notes that in locations where dams are present, local rainfall shortages continue to exacerbate violence while not adversely affecting agricultural wages, providing suggestive evidence against the labor market being a mediating mechanism (see Online Appendix), but Sarsons is unable to rule out the effects of market prices on real income or the effects of rainfall on non-agricultural or non-wage income. Hidalgo et al. (2010) examine Brazilian municipalities during 1988-2004 and find that locations with abnormally high or low annual rainfall have an increased risk of land invasions, which are attempts by small groups of landless farmers to forcefully redistribute land. In contrast to Sarsons' result, Hidalgo et al. demonstrate that extreme rainfall events that increase land invasion risk also reduce agricultural incomes, suggesting that income losses may play a role in triggering these invasions.

The studies that examine associations between climate variables and conflict at the highest frequency and the smallest spatial scale come from the United States, where data quality is high. Kenrick and Macfarlane (1986) demonstrate that individuals are more prone to hostile behavior on hot days using a field experiment where they frustrated drivers in Phoenix, Arizona and measured their honking behavior. Cohn and Rotton (1997) examined reported assaults in Minneapolis, Minnesota every three hours during 1987-1988 and found that violent attacks rose with higher temperatures. This basic result was later strengthened by the introduction of additional temporal controls (Bushman et al. 2005), was replicated in hotter areas (Rotton and Cohn 2000) and nationally ${ }^{9}$ (Anderson et al. 2000), and was shown to hold at the daily level for many individual municipal jurisdictions (Jacob et al. 2007). In the most detailed study yet, Ranson (2012) constructs a county-level panel of weather and crime over the period 1960-2009 and again shows that hotter temperatures increase a range of violent crimes. In a similar vein, Vrij et al. (1994) demonstrate that officers were more likely to use deadly force in a training simulation when confronted with threatening individuals in a hotter environment, and Larrick et al. (2011) found that US baseball pitchers are more likely to hit batters with the ball (a violent act) on hotter days. Interestingly, Larrick et al. (2011) provide evidence that their results describe intergroup retaliatory violence that escalates more rapidly on hot days.

\footnotetext{
${ }^{9}$ See also Anderson et al. (1997).
} 


\subsection{Modern global data}

Several studies of post-1900 samples are global in their coverage, something which is absent from the pre-1900 data. Levy et al. (2005) create a $2.5^{\circ}$ pixel-level global dataset for 1975-2002 and find that negative rainfall anomalies raise the risk of conflict onset. Dell et al. (2012) and Almer and Boes (2012) examine the effect of temperature on civil conflict incidence at the country level for a global sample of poor and all countries, respectively, using two different statistical approaches. Both studies obtain effect sizes that are similar to those of Burke et al. (2009), but in both cases the point estimates are too noisy to be statistically significant.

Burke and Leigh (2010) and Burke (2012) examine country-level data during 1963-2007 and 1963-2001, respectively, and find results consistent with Brückner and Ciccone (2010): temperature and precipitation changes that are correlated with economic contraction are also associated with a destabilization of the preexisting political balance, leading to abrupt institutional and leadership changes. Dell et al. (2012) also examine whether irregular leadership changes (eg. coups) are associated with high temperature years and find substantially larger effect sizes than Burke (2012) when they focus on countries below the median income level.

Salehyan and Hendrix (2012) study the effect of rainfall, temperature and the Palmer Drought Severity Index on terrorism attacks during 1979-2008, finding that attacks are significantly less likely in dry years, which they hypothesize may be due to resource constraints that prevent attacks in years of economic hardship. The logistical constraints of terrorist attacks may differ substantially from those of many other types of violence studied here, possibly explaining why the structure of this response is inverted.

Bergholt and Lujala (2012) are the only study to model the effect that floods and wind storms have on the onset of civil conflict (1980-2007), finding a small, negative and statistically insignificant effect. It is possible that these disasters, which are phenomenologically different from the rainfall and temperature variations studied above, have a fundamentally different impact on social conflict.

Finally, in the first existing study to link planetary-scale changes in climate with global patterns of conflict, Hsiang et al. (2011) demonstrate that civil conflict risk is associated with annual variations in the El Niño-Southern Oscillation (ENSO) during 1950-2004. Hsiang et al. find that annual conflict risk (ACR), defined as the probability that a randomly selected country begins a civil conflict in a given year, doubles throughout the tropics when the global climate shifts from the cooler and wetter La Niña phase to the hotter and drier El Niño phase. Hsiang et al. show that in the middle and high latitudes, where populations are not exposed to a strong interannual ENSO signal, ACR does not vary in phase with this global climate pattern, and that low-income countries are more sensitive to ENSO variations than high-income countries. For these low income countries, shifting the global climate from the more violent El Niño to the more peaceful La Niña has the same effect on conflict risk as raising that country's income by a factor of ten. Hsiang et al. are unable to determine which local variables, such as temperature or precipitation, mediate this response, but the study is the first to demonstrate that global climate changes, rather than just local or regional changes, have a measurable impact on conflict and stability around the world. Illustrating the importance of the global 
climate's influence, Hsiang et al. compute that $21 \%$ of conflicts since 1950 were attributable to movements in the global climate away from its most peaceful La Niña state.

\section{Conclusions}

The relationship between climate and conflict is one of immense policy interest, and is a topic that has received substantial recent attention from researchers around the world. This is the first review to collect the rapidly expanding body of literature linking climatic fluctuations to conflict and instability, and to document the remarkable convergence in findings. Studies best positioned to make rigorous causal claims overwhelmingly indicate strong linkages between climatic anomalies and conflict and social instability. Furthermore, this growing literature demonstrates that climate's influence on security persists in both historical and modern periods, is generalizable to populations around the globe, arises from climatic events that are both rapid and gradual, and influences numerous types of conflict that range across all spatial scales. The majority of studies suggest that conflict increases and social stability decreases when temperatures are hot and precipitation is extreme, but in situations where average temperature is already temperate, anomalously low temperatures may also undermine stability.

At the same time, the literature to date is less successful in demonstrating how historical changes in climate have shaped conflict and social stability. Many different potential mechanisms have been suggested, and existing studies generally have difficulty distinguishing between possible explanations. Understanding the mechanisms linking climate to conflict is the area that we believe is most ripe for future quantitative research. In the Online Appendix, we outline eight of the leading hypotheses that might explain this association.

\subsection{Implications for anthropogenic climate change}

Climatic changes induced by human activity are expected to increase the inter-annual variability of rainfall for many locations and to raise annual mean temperatures globally (Meehl et al. 2007; IPCC 2012). If future populations behave similarly to historical populations, then the available evidence strongly suggests that both of these changes should increase the risk of violent conflicts and socio-political instability for most populations in the topics and subtropics, as well as some populations in middle latitudes. There is no evidence that the gradualness of mean temperature changes will mitigate their impact, although it is plausible that future populations will adapt in previously unobserved ways.

Because existing analyses are unable to determine the mechanisms through which climatic changes influence the likelihood of conflict and instability, projections of future impacts should be made with reasonable caution. However, it is equally important to recognize that the absence of a single mechanistic explanation for the observed association does not imply that we lack evidence of a causal association. The studies in this review were selected for their ability to provide reliable causal inferences and they overwhelmingly indicate that climatic variables are one of many important causal factors in human conflict, suggesting that the potential effects of 
future climate change on violence and instability may represent a key vulnerability of modern societies. We hope that future research will reduce the number of competing hypotheses that attempt to explain this empirical regularity, and thus provide more targeted information to policymakers trying to minimize the human cost of future conflicts.

Acknowledgements We thank Halvard Buhaug, Mark Cane, François Gemenne, Cullen Hendrix, Edward Miguel, Kyle Meng, Michael Oppenheimer, Idean Salehyan, Stacy VanDeveer, and 3 referees for comments. S.M.H. is funded by a Postdoctoral Fellowship in Science, Technology \& Environmental Policy (Princeton); M.B. is funded by a National Science Foundation Graduate Research Fellowship. This review was commissioned and funded in part by the French Ministry of Defence and the British Department of Energy and Climate Change, via the British Embassy in Paris.

\section{References}

Almer C, Boes S (2012) Climate (change) and conflict: resolving a puzzle of association and causation. SSRN. http://papers.ssrn.com/sol3/papers.cfm?abstract_id=2035431. Accessed 27 Mar 2013

Anderson C et al. (2000) Temperature and aggression. Adv Exp Soc Psychol 32:63-133

Anderson C, Bushman B, Groom R (1997) Hot years and serious and deadly assault: empirical tests of the heat hypothesis. J Pers Soc Psychol 73(6):1213

Angrist JD, Pischke JS (2008) Mostly harmless econometrics. Princeton

Bai Y, Kung J (2010) Climate shocks and sino-nomadic conflict. Rev Econ Stat 93:970-981

Bergholt D, Lujala P (2012) Climate-related natural disasters, economic growth, and armed civil conflict. J Peace Res 49(1):147-162

Bernauer T, Böhmelt T, Koubi V (2012) Environmental changes and violent conflict. Environ Res Lett 7. doi:10.1088/1748-9326/7/1/015601

Blattman C, Miguel E (2010) Civil war. J Econ Lit 48:3-57

Bohlken AT, Sergenti EJ (2010) Economic growth and ethnic violence: an empirical investigation of Hindu-Muslim riots in India. J Peace Res 47:589-600

Brückner M, Ciccone A (2011) Rain and the democratic window of opportunity. Econometrica 79(3):923-947

Buckley B, et al. (2010) Climate as a contributing factor in the demise of Angkor, Cambodia. PNAS 107(15)

Buhaug H (2010) Climate not to blame for African civil wars. PNAS

Büntgen U et al. (2011) 2500 years of European climate variability and human susceptibility. Science 331(6017):578-582

Burke M et al. (2009) Warming increases the risk of civil war in Africa. PNAS

Burke $\mathrm{M}$ et al. (2010a) Climate and civil war: is the relationship robust? NBER. http://www. nber.org/papers/w16440. Accessed 19 Apr 2012

Burke MB et al. (2010b) Climate robustly linked to African civil war. PNAS 107(51):E185

Burke MB et al. (2010c) Reply to Sutton et al.: relationship between temperature and conflict is robust. PNAS 107(25):E103

Burke PJ (2012) Economic growth and political survival. BEJ Macroecon 12(1):1-43

Burke PJ, Leigh A (2010) Do output contractions trigger democratic change? AEJ Macroecon 2(4):124-157

Bushman B, Wang M, Anderson C (2005) Is the curve relating temperature to aggression linear or curvilinear? J Pers Soc Psychol 89:74-77

Cervellati M, Sunde U, Valmori S (2011) Disease environment and civil conflicts. IZA. http://papers. ssrn.com/abstract=1806415. Accessed 19 Apr 2012

Chaney E (2013) Revolt on the Nile: economic shocks, religion and political influence. Econometrica 81(5):2033-2053

Ciccone A (2011) Economic shocks and civil conflict: a comment. AEJ App Econ 3:215-227

Cohn E, Rotton J (1997) Assault as a function of time and temperature: a moderator-variable timeseries analysis. J Pers Soc Psychol 72:1322-1334

Couttenier M, Soubeyran R (2013) Drought and civil war in Sub-Saharan Africa. Econ J. doi:10.1111/ecoj.12042 
Cullen H et al. (2000) Climate change and the collapse of the Akkadian empire: evidence from the deep sea. Geology 28(4):379-382

Dell M, Jones BF, Olken BA (2012) Climate change and economic growth: Evidence from the last half century. AEJ Macroecon 4:66-95

DeMenocal P (2001) Cultural responses to climate change during the late Holocene. Science 292(5517):667-673

Fjelde H, von Uexkull N (2012) Climate triggers: rainfall anomalies, vulnerability and communal conflict in sub-Saharan Africa. Pol Geo 31:444-453

Freedman D (1991) Statistical models and shoe leather. Sociol Methodol 21:291-313

Gleditsch N (2012) Whither the weather? climate change and conflict. J Peace Res 3-9

Graff Zivin J, Neidell M (2013) Temperature and the allocation of time: implications for climate change. J Labor Econ (in press)

Harari M, La Ferrara E (2011) Conflict, climate and cells: a disaggregated analysis. SSRN. http://www-2.iies.su.se/Nobel2012/Papers/LaFerrara_Harari.pdf. Accessed 19 Apr 2012

Haug G et al. (2003) Climate and the collapse of Maya civilization. Science 299(5613):1731-1735

Hendrix CS, Salehyan I (2012) Climate change, rainfall, and social conflict in Africa. J Peace Res 49(1):35-50

Hidalgo F et al. (2010) Economic determinants of land invasions. Rev Econ Stat 92(3)

Holland P (1986) Statistics and causal inference. J Am Stat Assoc 81:945-960

Hsiang S, Meng K, Cane M (2011) Civil conflicts are associated with the global climate. Nature 476(7361):438-441

Hsiang SM (2010) Temperatures and cyclones strongly associated with economic production in the Caribbean and Central America. PNAS 107(35):15367-15372

Hsiang SM, Burke M, Miguel E (2013) Quantifying the influence of climate on human conflict. Science 341. doi:10.1126/science. 1235367

IPCC (2012) SREX special report. Cambridge

Jacob B, Lefgren L, Moretti E (2007) The dynamics of criminal behavior: evidence from weather shocks. J Hum Resour 42:489-527

Kennett D et al. (2012) Development and disintegration of maya political systems in response to climate change. Science 338(6108):788-791

Kenrick DT, Macfarlane SW (1986) Ambient temperature and horn honking: a field study of the heat/aggression relationship. Environ Behavior 18(2):179-191

Kung JK, Ma C (2012) Can cultural norms reduce conflicts? Confucianism and peasant rebellions in Qing China. AHEC. http://ahec2012.org/papers/S6B-2_Kai-singKung_Ma.pdf. Accessed 8 Feb 2013

Kuper R, Kröpelin S (2006) Climate-controlled Holocene occupation in the Sahara: motor of Africa's evolution. Science 313(5788):803-807

Larrick RP et al. (2011) Temper, temperature, and temptation: Heat-related retaliation in baseball. Psych Sci 22:423-428

Levy M et al. (2005) Freshwater availability anomalies and outbreak of internal war: results from a global spatial time series analysis. http://www.ciesin.columbia.edu/pdf/waterconflict.pdf. Accessed 19 Apr 2012

Lobell D, Burke M (2010) Climate change and food security: adapting agriculture to a warmer world. Springer

Maddison A (2010) Historical statistics of the world economy: 1-2008 AD. University of Groningen

Meehl GA, Stocker T, Collins W, Friedlingstein P, Gaye A, Gregory J, Kitoh A et al (2007) Climate change 2007: the physical science basis. Contribution of working group I to the fourth assessment report of the intergovernmental panel on climate change, pp 747-846

Mehlum H, Miguel E, Torvik R (2006) Poverty and crime in 19th century Germany. J Urb Econ 59(3):370-388

Miguel E (2005) Poverty and witch killing. Rev Econ Stud 72(4):1153-1172

Miguel E, Satyanath S (2011) Re-examining economic shocks and civil conflict. Am Econ J Applied Economics 3:1-6

Miguel E, Satyanath S, Sergenti E (2004) Economic shocks and civil conflict: an instrumental variables approach. J Pol Econ 112(4):725-753

O'Loughlin J et al. (2012) Climate variability and conflict risk in East Africa, 1990-2009. PNAS

Pasquale B, Travaglianti M (2009) Guns, growth \& geography: the subnational origins of insurgency. NYU. https://files.nyu.edu/bp730/public/guns_growth.pdf. Accessed 19 Apr 2012

Patterson W et al. (2010) Two millennia of North Atlantic seasonality and implications for Norse colonies. PNAS 107(12):5306-5310 
Ranson M (2012) Crime, weather and climate change. J Environ Econ Manage (in press)

Rotton J, Cohn E (2000) Violence is a curvilinear function of temperature in Dallas. J Pers Soc Psychol 78(6):1074-1081

Rubin DB (1974) Estimating causal effects of treatments in rancomized and nonrandomized studies. J Educ Psychol 66(5):688-701

Salehyan I, Hendrix CS (2012) Climate shocks and political violence. ISA

Sarsons H (2011) Rainfall and conflict. Harvard. http://www.econ.yale.edu/conference/neudc11/ papers/paper_199.pdf. Accessed 19 Feb 2013

Scheffran J et al. (2012) Climate change and violent conflict. Science

Schlenker W, Roberts M (2009) Nonlinear temperature effects indicate severe damages to U.S. crop yields under climate change. PNAS 106(37):391-398

Stahle D et al. (1998) The lost colony and Jamestown droughts. Science 280(5363):564-567

Sutton AE et al. (2010) Does warming increase the risk of civil war in Africa? PNAS 107(25):E102

Theisen O, Holtermann H, Buhaug H (2011) Climate wars? Assessing the claim that drought breeds conflict. Int Sec 36(3):79-106

Theisen OM (2012) Climate clashes? Weather variability, land pressure, and organized violence in Kenya, 1989-2004. J Peace Res 49(1):79-106

Tol R, Wagner S (2010) Climate change and violent conflict in Europe over the last millennium. Clim Change 99:65-79

Vrij A, der Steen JV, Koppelaar L (1994) Aggression of police officers as a function of temperature: An experiment with the fire arms training system. J Com App Soc Psych 4(5):365-370

Witschi H (2001) A short history of lung cancer. Toxicol Sci 64(1):4-6

Yancheva G et al. (2007) Influence of the intertropical convergence zone on the East Asian monsoon. Nature 445:74-77

Zhang D et al. (2006) Climatic change, wars and dynastic cycles in China over the last millennium. Clim Change 76:459-477

Zhang D et al. (2011) The causality analysis of climate change and large-scale human crisis. PNAS 108(42):17296-17301

Zhang DD et al. (2007) Global climate change, war, and population decline in recent human history. PNAS 